\title{
Views collide over fate of accelerator
}

Its parts have been dismembered, its roof is leaking, and a wall is missing. Now activists and scientists are squabbling over whether to completely raze the Bevatron - one of the most important particle accelerators ever built.

The remains of the Bevatron, which was decommissioned more than a decade ago, take up prime real estate on the Lawrence Berkeley National Laboratory's campus in Berkeley, California. Scientists at the lab want to tear it down to make way for fresh projects. But locals, many of whom oppose the demolition because of concerns about the possible release of contaminants, say they want to see it made into a museum.

On 3 August, the city council's Landmarks and Preservation Commission dealt a blow to those wanting landmark status for the accelerator by voting to recognize the Bevatron's legacy without protecting the building. Nevertheless, landmark advocates have vowed to continue fighting.

"It's truly a landmark, a very unique building," says Mark McDonald, who sits on the City of Berkeley's Peace and Justice Commission. "Somebody called it the world's

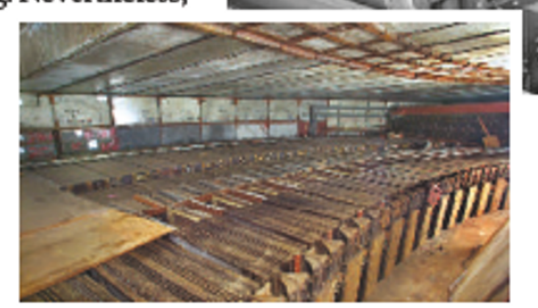

machine, and is currently pursuing its demolition. "The value of the Bevatron is for the science that was done there," says Feinberg. ${ }^{\alpha}$ The building is nothing really special."

Feinberg declined to comment on the latest interest in preserving the building, but some lab officials quietly believe that it's the walls, not the accelerator, that are of real concern to local groups. The building was constructed using transite, a composite of asbestos and cement, which releases asbestos fibres when it is broken

\section{Bevatron's greatest hits}

Most of the discoveries made in the Bevatron occurred early on in its 40-year history.

1955 Owen Chamberlain and Emilio Segrè use the Bevatron to find the antip roton, for which they win the Nobel prize in 1959.

1956 Bruce Cork's team discovers the antineutron using the accelerator.

1956 Tsung-Dao Lee and Chen Ning Yang suggest using the Bevatron to test 'parity violation', the idea that somelaws of nature are not symmetric.

1960 Bogdan Maglich reports a unique particle called $Y^{\star}(1385)$, which points to the existence of quarks.

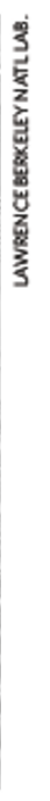

up. Community members have expressed fears that razing the Bevatron would involve moving large amounts of loose asbestos through the city of Berkeley. Environmentalists also fear that lead and other contaminants from the building site could escape into the water table.

Pamela Sihvola, who co-chairs the Committee to Minimize Toxic Waste - a local watchdog group that monitors the laboratory - is among those pushing to preserve the Bevatron. ${ }^{\alpha}$ The EPA says that the best way to deal with lead and asbestos is to manage it in place," she says. "All we want the laboratory to do is consider a reuse alternative," she says. "It could be a living science museum and education centre" Chamberlain supported the idea, and even wrote a letter advocating the conversion of the Bevatron before his death in February, she notes.

McDonald adds that the centre would immortalize the Berkeley Lab's most famous work. "We haven't had a lot of Nobel prizes up there lately, he says. "There's nothing wrong with paying a tribute."

But Feinberg disagrees. With limited space, he argues, the Bevatron site is more valuable to lab researchers than the ageing machine it contains. "A fitting memorial," he says, "would be to re-use that site to do cutting-edge science."

The lab is now preparing the environmental-impact statement needed to proceed with demolition. Sihvola is gearing up for a fresh round of debate with the full city council: ${ }^{\alpha}$ Our attempts to preserve the building will continue," she vows.

Geoff Brumfiel 